\title{
Effect of high fat consumption on cell proliferation activity of colorectal mucosa and on soluble faecal bile acids
}

\author{
JONA STADLER, HARTLEY S STERN, KA SING YEUNG, \\ VALERIE MCGUIRE, RUDOLF FURRER, NORMAN MARCON, \\ AND W R BRUCE \\ From the Ludwig Institute for Cancer Research, Toronto Branch, Department of Surgery, Mount Sinai \\ Hospital and Department of Gastroenterology, Wellesley Hospital, University of Toronto, Ontario, Canada
}

SUmmary To assess the effect of fat consumption on the proliferation of the rectal mucosa, 30 normal volunteers ( 22 to 71 years) were randomly allocated to three groups: (a) basal low fat diet containing $30 \mathrm{~g}$ of fat per day; (b) the basal diet with doses of $30 \mathrm{~g}$ corn oil taken with each of the three meals: $120 \mathrm{~g}$ fat/day; (c) the basal diet with one dose of $90 \mathrm{~g}$ corn oil after the last meal: $120 \mathrm{~g}$ fat $/ \mathrm{day}$. Rectal biopsies were taken $15 \mathrm{~cm}$ from the anal verge after five days on the diets and mucosal cell proliferation was measured by labelling index (LI). The LI was significantly $(p<0 \cdot 01)$ higher in group (c) $(9 \cdot 2)$ than in group (a) (5.9), with group (b) intermediate (6.8). In multiple stepwise regression analysis, the data were best fitted with age and the variable indicating fat consumed as a bolus as predictors of $\mathrm{LI}\left(\mathbf{r}^{2}=0.39, \mathrm{p}<0 \cdot 001\right)$. In separate analyses the regression coefficient with age in the fat bolus group was $0.23, p<0.001$. There was some tendency towards lower bile acids in the faecal water in group (a) than in groups (b) and (c) following the diets and between the bile acids and LI (for lithocholic acid $r=0.48, p=0.01$ ). These data show that dietary fat given as a bolus can lead to an increase in the proliferation of human colonic cells, possibly as a consequence of raised levels of cytotoxic acidic lipids in the faecal stream.

Recent studies have shown that raised levels of dietary fat can lead to an increase in the proliferation of colonic epithelial cells of experimental animals. The increase in proliferation, marked by a raised frequency of ${ }^{3} \mathrm{H}$-thymidine labelled cells and accumulation of mitotic figures in the cells of the colonic crypts, is most clearly evident a few hours after an oral bolus of fat' but may also be seen after prolonged feedings with diets comprised of $20 \%$ or more of dietary fat.: The mechanism responsible for the proliferation is not known, but short term studies with boluses suggest that it could represent a compensatory proliferation after the loss or damage to surface epithelial cells.' The damage could result from bile acids and fatty acids in solution. They are

Address for correspondence: Dr W Rohert Bruce, Ludwig Institute for Cancer Research, 9 Farl Street. Toronto, Ontario M4Y IM4. Canada

Received for publication 14 April 1988. known to be toxic to the colonic epithelium. ${ }^{34}$ Their concentration in solution in faeces is known to be affected by diet."

This study seeks to answer two questions. First, is the proliferation of cells in the colonic mucosa influenced by the consumption of dietary fat and is this most marked when fat is consumed as a bolus? And second, is the proliferation rate associated with an increase in the concentration of bile acids or fatty acids in the aqueous phase of the faeces? To answer these questions in humans we administered dietary fat as corn oil to groups of volunteers either with their meals or as boluses nightly (for a period of five days). Proliferation was assessed by colorectal biopsies and in vitro thymidine labelling of S-phase cells. In addition, the concentration of bile acids and fatty acids in the faeces was measured to determine whether the proliferation in the mucosa was related to the levels of these compounds. 


\section{Methods}

SUBJECTS AND PROTOCOL

Thirty volunteers from the staff of the Princess Margaret Hospital and the Ludwig Institute were randomly allocated to three intervention groups in a protocol reviewed by the ethics committee of the University of Toronto and the Clinical Trials Committee of the hospital. Each volunteer, after instruction by the study dietitian, provided three day food records, the records being made on two week days and one weekend day. These records were analysed by the Nutrition Coding Center (NCC) at the University of Minnesota, Minneapolis.

During the intervention period of five days all the subjects were given a basal diet containing $30 \mathrm{~g}$ fat/ day (Table 1). The food was prepared by the hospital kitchen and the subjects ate their breakfasts, noon, and evening meals in the hospital cafeteria for the

Table 1 Description of intervention: nutritional analysis per day for the three groups

\begin{tabular}{|c|c|c|}
\hline \multicolumn{3}{|c|}{ Nutritional analysis } \\
\hline & Calories & $1728 \mathrm{Kcal}$ \\
\hline & Proteins & $9.5 \mathrm{~g}$ \\
\hline & Carbohydrates & $267 \mathrm{~g}$ \\
\hline & (Starch & $9(0 \mathrm{~g})$ \\
\hline & Fat & $30 \mathrm{~g}$ \\
\hline & Calcium & $4(x) \mathrm{mg}$ \\
\hline & Fibre & $16 \mathrm{~g}$ \\
\hline Group (b) & High fat & \\
\hline & \multicolumn{2}{|c|}{ Above low fat diet +3 times $30 \mathrm{~g}$ corn oil with meals } \\
\hline Group (c) & \multicolumn{2}{|c|}{ Large bolus of fat } \\
\hline & \multicolumn{2}{|c|}{$\begin{array}{l}\text { Low fat diet }+90 \mathrm{~g} \text { corn oil every evening } 4-6 \mathrm{~h} \text { after last } \\
\text { meal }\end{array}$} \\
\hline
\end{tabular}

Diet for group (a)

Breakfast

Noon meal

Evening meal

Evening snack

$20 \mathrm{ml}$ skim milk

50) $\mathrm{g}$ whole wheat toast

$10 \mathrm{~g}$ diet butter

20 g jam

12) $\mathrm{ml}$ orange juice

$120 \mathrm{mg}$ orange juice

5) g whole wheat bread

$10 \mathrm{~g}$ diet butter*

10 g diet mayonnaise*

I(X) g chicken white meat

$100 \mathrm{~g}$ apple

$3(x) \mathrm{ml}$ diet soft drink

$85 \mathrm{~g}$ roast beef

$160)$ g potato, boiled

$7.5 \mathrm{~g}$ carrot, steamed

$4.5 \mathrm{~g}$ peas, steamed

$50 \mathrm{~g}$ Kaiser roll

$10 \mathrm{~g}$ diet hutter*

10() g banana

$120 \mathrm{ml}$ orange juice

$120 \mathrm{ml}$ orange juice

30) g hard candy

*Diet butter: contains half the amount of fat and calories of regular butter; diet mayonnaise: contains half the amount of fat and calories as regular mayonnaise. entire period. Group (a) (low fat diet) was given only the basal diet. Group (b) (high fat) was given an additional $30 \mathrm{~g}$ corn oil with each of the three meals, the total fat consumption for group (b) being $120 \mathrm{~g} /$ day. Group (c) (fat bolus) ingested $90 \mathrm{~g}$ corn oil at night as a bolus, four to six hours after the last meal, the supplementary fat in this case being taken with a small amount of orange juice, the total fat consumption in group (c) being also $120 \mathrm{~g} /$ day. In general the diets were well tolerated with little change in bowel habit, though three of the subjects in group (c) complained of some abdominal cramping and noted looser stools than normal. On the sixth day all the volunteers returned for a flexible sigmoidoscopic examination between 9 am and 12 noon during which two colorectal biopsies were taken at about $15 \mathrm{~cm}$ from the anal verge. Of the 30 volunteers, one withdrew before biopsy, and biopsy specimen from one volunteer was damaged during the procedure and could not be scored. A total of 28 participants thus provided biopsies for the study. Faecal specimens from one bowel movement were collected from each of the 27 subjects and promptly delivered to the laboratory before the intervention and on the sixth day, in the latter case, being the last specimen in contact with the biopsied mucosa.

\section{A BORATORY PROCEDURES}

Faecal water was prepared from the faecal samples by the method previously described.' Briefly, aliquots of the fresh stool sample were centrifuged at $20000 \times g$ for two hours at $18-20^{\circ} \mathrm{C}$. The supernatant water was carefully removed and assayed for fatty acids, neutral steroids and bile acids by gas chromatography after derivatisation. ${ }^{\circ}$ Results are given for the average of two determinations.

The biopsy specimens were each examined and cleaned under a dissecting microscope in $15 \mathrm{ml}$ alphaMEM media and then transferred in $2 \mathrm{ml}$ sterile septum fitted vials (Varian, \#96-0000 99-(00) containing $1.2 \mathrm{ml}$ alpha-MEM medium. Thymidine labelling was carried out in a hyperbaric oxygen environment that has been shown to yield results similar to those obtained in vivo. ${ }^{7}$ Six microlitres of a solution of ${ }^{3} \mathrm{H}$ thymidine $(40 \mu \mathrm{Ci} / \mathrm{mmol})$ was added to give a final concentration of $5 \mu \mathrm{Ci} / \mathrm{ml}$, and $2.4 \mathrm{ml}$ oxygen was injected into each vial which was then incubated on a rocking stage at $37^{\circ} \mathrm{C}$ for 90 minutes. After incubation the pressure was released, the specimens were washed in Krebs-Ringer at room temperature, oriented mucosa side up on a small piece of Gelfoam and fixed in $10 \%$ phosphate buffered formalin. Sections were mounted for autoradiography as previously described. ${ }^{7 \times}$ Full crypt sections were scored for labelled cells without the technologist knowing from which group the specimen came. Data on cell 
position (expressed in number of cells from the bottom of the crypt), crypt and cell number were recorded directly on a microcomputer for analysis. The labelling index (LI) in percentage was computed for each specimen and for each subject by dividing the number of labelled cells scored by the total number of cells counted. Because of differences in the exact orientation of successive biopsies the number of crypts and cells scored differed significantly among the biopsies (from 424 to 10000 cells/2 specimens combined).

\section{STATISTICAL ANALYSIS}

Statistical Analysis System ${ }^{4}$ was used to generate statistics for hypotheses testing. To study the relationship between fat consumption and labelling index, univariate analyses ( $t$ test, analysis of variance and Wilcoxon's rank-sum test) were used. Because the number of cells scored varied between biopsies, each LI observed was weighted by the reciprocal of the square of its standard error, "' where the standard error of each observation $(p)=p(1-p) /$ number of cells scored. The conclusion of each analysis was not affected by the use of crude or weighted statistics; weighted statistics were presented unless specified otherwise. In regression analyses, two variables,

Table 2 Distributions of age, sex, body weight and nutrient intakes before intervention for the three intervention groups

\begin{tabular}{|c|c|c|c|c|}
\hline Variable & Group (a) & Group (b) & Group (c) & $p^{\dagger}$ \\
\hline n & 10 & 8 & 10 & \\
\hline Sex (male:female) & $6: 4$ & $5: 3$ & $6: 4$ & \\
\hline Age & $\begin{array}{c}47 \cdot 5^{*} \\
(12 \cdot 9) \ddagger\end{array}$ & $\begin{array}{l}43 \cdot 6 \\
(9 \cdot 7)\end{array}$ & $\begin{array}{c}35 \cdot 8 \\
(12 \cdot 9)\end{array}$ & $0 \cdot 10$ \\
\hline Body weight (kg) & $\begin{array}{l}65 \cdot 9 \\
(8 \cdot 3)\end{array}$ & $\begin{array}{c}71 \cdot 5 \\
(12 \cdot 4)\end{array}$ & $\begin{array}{c}67 \cdot 8 \\
(15 \cdot 0)\end{array}$ & 0.57 \\
\hline Total food energy Kcal/day & $\begin{array}{l}2089 \\
(697)\end{array}$ & $\begin{array}{l}2044 \\
(278)\end{array}$ & $\begin{array}{l}2142 \\
(605)\end{array}$ & 0.93 \\
\hline Total protein g/day & $\begin{array}{c}92 \cdot 1 \\
(37 \cdot 9)\end{array}$ & $\begin{array}{c}94 \cdot 2 \\
(32 \cdot 9)\end{array}$ & $\begin{array}{c}87 \cdot 7 \\
(24 \cdot 8)\end{array}$ & $0 \cdot 91$ \\
\hline Total fat g/day & $\begin{array}{c}81 \cdot 9 \\
(36 \cdot 3)\end{array}$ & $\begin{array}{c}82 \cdot 9 \\
(20 \cdot 7)\end{array}$ & $\begin{array}{c}84 \cdot 1 \\
(34 \cdot 9)\end{array}$ & 0.99 \\
\hline Carbohydrate g/day & $\begin{array}{l}233 \cdot 6 \\
(62 \cdot 2)\end{array}$ & $\begin{array}{l}229.9 \\
(37 \cdot 0)\end{array}$ & $\begin{array}{l}256 \cdot 7 \\
(55 \cdot 3)\end{array}$ & $0 \cdot 51$ \\
\hline Fibre g/day & $\begin{array}{l}16 \cdot 5 \\
(6 \cdot 0)\end{array}$ & $\begin{array}{l}17 \cdot 1 \\
(7 \cdot 7)\end{array}$ & $\begin{array}{c}22 \cdot 6 \\
(6 \cdot 8)\end{array}$ & $0 \cdot 11$ \\
\hline Vitamin A IU/day & $\begin{array}{c}7839 \\
(4958)\end{array}$ & $\begin{array}{l}13508 \\
(7560)\end{array}$ & $\begin{array}{c}8833 \\
(3795)\end{array}$ & 0.09 \\
\hline Calcium mg/day & $\begin{array}{c}799 \\
(277)\end{array}$ & $\begin{array}{l}1045 \\
(475)\end{array}$ & $\begin{array}{l}1097 \\
(260)\end{array}$ & $0 \cdot 15$ \\
\hline Phoshporus mg/day & $\begin{array}{l}1394 \\
(414)\end{array}$ & $\begin{array}{l}1555 \\
(496)\end{array}$ & $\begin{array}{l}1657 \\
(381)\end{array}$ & $0 \cdot 40$ \\
\hline Alcohol $\ddagger$ g/day & $\begin{array}{c}5 \cdot 7 \\
(0-34 \cdot 7)\end{array}$ & $\begin{array}{c}1 \cdot 9 \\
(0-21 \cdot 0)\end{array}$ & $\begin{array}{c}6 \cdot 0 \\
(0-38 \cdot 0)\end{array}$ & 0.518 \\
\hline
\end{tabular}

*Group means are given, standard deviations in parentheses: †significance level from analyses of variance: $\ddagger$ distributions of alcohol consumption within each group are skewed, medians and range in parentheses for group (a), (b), and (c) are given: $\S s i g n i f i c a n c e ~ l e v e l$ from Wilcoxon's rank-sum test. 'high fat' and 'high fat bolus' were created to indicate group membership. Group (a) scored ' 0 ' on both variables. Group (b) scored ' 1 ' on 'high fat' and ' 0 ' on 'high fat bolus'. Group (c) scored ' 1 ' on 'high fat' and ' 1 ' on 'high fat bolus'. Correlation analyses (Pearson's) were used to assess confounding variables and multiple regression analyses were used to assess the effect of intervention with adjustment for confounding variables.

To study the relationship between fat consumption, soluble bile acids and labelling index, nonparametric tests (Wilcoxon's rank-sum test, Wilcoxon's signed-rank test for paired statistics, median test and Spearman's correlation analyses) were used because the distributions of bile acids were not symmetric.

\section{Results}

COMPARISON BETWEEN THE THREEGROUPS

BEFORE INTERVENTION

The three groups of subjects were similar with respect to sex, body weight, nutrient intakes before the intervention - fat, protein, calcium, phosphorus as well as total daily food energy and alcohol. Group (c) participants were younger and consumed more fibre, while group (b) consumed more vitamin A, but no statistically significant differences were apparent (Table 2).

LABELLING INDEX AFTER THE INTERVENTION The tritiated thymidine labelling index of the colonic epithelial cells for each of the subjects is shown in Figure 1a and the mean values and labelling parameters are given in Table 3 . The crude mean LI for the three groups (a), (b), and (c), are 5.9, 6.8, and $9 \cdot 2 \%$ respectively. The high fat bolus group (c), is significantly higher than the low fat group (a) by the $t$ test $(p=0.01)$ and the Wilxocon's rank-sum test $(p=$ $0 \cdot 02)$. The difference remained $(p=0.001)$ when each observation was weighed as described in the Methods section. The mean position of the labelled cells and the number of cells per crypt were similar in the three groups.

LABELLING INDEX AND AGE

To assess the effect of intervention on LI with adjustment for possible confounding variables, stepwise multiple regression analyses were performed. Initially age, body weight, and the two indicator variables for group membership were included. The best fitted model is: $L I=-0.35+0 \cdot 13 \times$ age $+4 \cdot 78 \times$ group (c) membership, with $r^{2}=0 \cdot 39 . p=0.001$ for the whole model. Regression coefficients for age and group (c) membership are significant at $p=0.02$ and $\mathrm{p}=0.0006$ respectively. Inclusion of the interaction term (age with group) did not improve $r^{2}$. Figure $1 b$ 

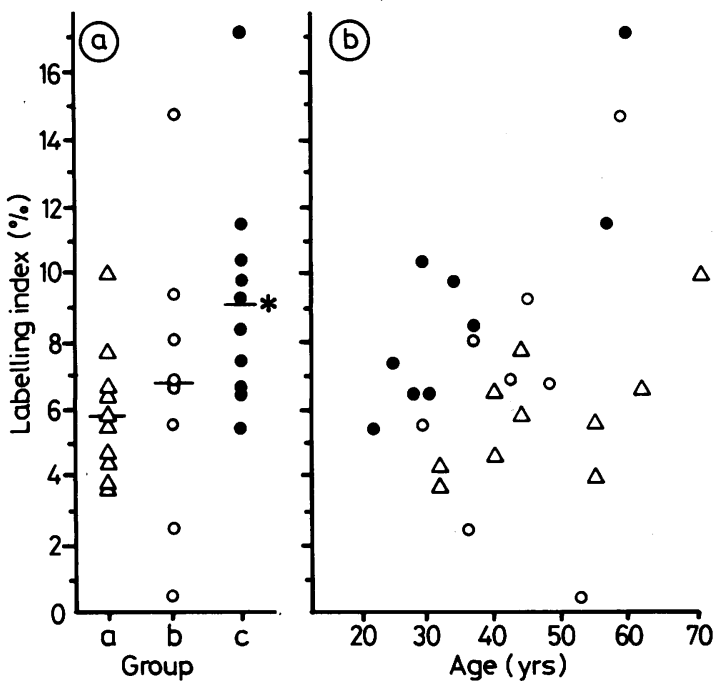

Fig. 1 (a) ${ }^{3} \mathrm{H}$-thymidine labelling indices of colorectal mucosal cells in normal healthy volunteers after five days of intervention; group $(a)(\Delta)$ - basal diet, group (b) $(O)$ basal diet and three doses of $30 \mathrm{~g}$ corn oil per day, group (c) (O) - basal diet and one dose of $90 \mathrm{~g}$ corn oil per day. *Significantly higher than group (a) $(p=0.01)$. (b) Association between labelling index and age for the three intervention groups. Group $(a)(\triangle)$, group (b) $(O)$, group (c) (O).

illustrates the association between age and labelling index for the three intervention groups.

To further explore the possibility of an interaction between age and fat intake on LI, regression analyses were performed on the three groups separately. The effect of age seemed weak in the low fat group (a) $(b=0.05, p=0.28)$, stronger in the high fat group; (b) $(b=0 \cdot 17, p=0 \cdot 45)$, and significant in the fat bolus group; (c) $(b=0.23, p=0.001)$. While this result suggests the possibility of interaction between the effect of age and fat intake as a bolus - that is, increase of LI occurs with increase in age only under the influence of consuming a large bolus of fat, the present study cannot exclude the possibility that age might have effects on LI under low fat consumption or high fat consumption in three separate meals because of the small sample size.

LABELLING INDEX AND SOLUBLE BILE ACIDS The concentrations of bile acids, fatty acids and neutral steroids in the faecal water for the three groups before and after intervention are given in Table 4 . The differences between the three groups for all three measures are not statistically significant by the Wilcoxon's rank-sum test and median test. By Wilcoxon's signed rank test, significant decrease after intervention was detected in deoxycholic acid in group (a); a significant increase after intervention was detected in total bile acids in group (b).

There was as expected no association between the labelling index and the faecal soluble bile acid, fatty acid or neutral steroid levels measured in the faecal specimens obtained before the intervention. The labelling index and the bile acid measures of the faeces obtained shortly after interventions were, however, associated. When Spearman's Correlation Analyses were done, the labelling index was clearly related to these bile acid levels (lithocholic acid, $r_{\mathrm{s}}=$ $0.48, p=0.01$ and deoxycholic acid, $r_{s}=0.34, p=0.07$, total bile acids, $r_{s}=0.41, p=0.03$ ). Less marked effects were seen with the faecal fatty acids $\left(r_{s}=0.35\right.$, $p=0.07)$ and no association was seen with the concentration of neutral steroids $\left(r_{s}=0 \cdot 02, p=0 \cdot 91\right)$.

\section{Discussion}

We have shown that dietary fat can influence the proliferation of cells in the colonic mucosa in this short term study. The group with supplementary fat as a bolus had a higher LI than the other two groups. We have also found that the older individuals on high fat diets have a higher LI than the younger. The first finding is consistent with the findings from animal experiments; the effect of age was unexpected.

The labelling index based on tritiated thymidine labelling has frequently been used as a measure of cellular proliferation in studies in man, ${ }^{11}{ }^{12}$ but this use should be taken with caution. It is evident first, that

Table 3 Measures of cell proliferation after intervention

\begin{tabular}{|c|c|c|c|c|c|c|}
\hline $\begin{array}{l}\text { Measure of cell proliferation } \\
\text { Labellịng index }\end{array}$ & Group (a) $n=10$ & Group (b) $n=8$ & Group (c) $n=10$ & (a) $v($ c) & (a) $v$ (b) & (b) $v(\mathrm{c})$ \\
\hline Crude means (standard deviation) & $5.9(1.9)$ & $6 \cdot 8(4 \cdot 3)$ & $9 \cdot 2(3 \cdot 4)$ & $0 \cdot 01 \ddagger$ & 0.59 & $0 \cdot 20$ \\
\hline Weighted means* & $5 \cdot 5$ & $6 \cdot 2$ & $9 \cdot 0$ & 0.001 & 0.51 & $0 \cdot 17$ \\
\hline Position of labelled cells $\dagger$ & $17 \cdot 2(2 \cdot 2)$ & $14 \cdot 4(6 \cdot 0)$ & $17 \cdot 4(2 \cdot 7)$ & $0 \cdot 78$ & $0 \cdot 24$ & 0.21 \\
\hline Cells/crypt column (n) & $53 \cdot 1(5 \cdot 9)$ & $43 \cdot 5(18 \cdot 1)$ & $49 \cdot 6(7 \cdot 2)$ & $0 \cdot 25$ & $0 \cdot 19$ & $0 \cdot 39$ \\
\hline Average number of cells scored/specimen & $2135(981)$ & $1308(1188)$ & $2124(1375)$ & 0.98 & $0 \cdot 12$ & $0 \cdot 20$ \\
\hline
\end{tabular}

*Each observation is weighted by the reciprocal of the square of its standard error; teach cell is given a position as number of cells from the bottom of the crypt: $\ddagger$ significance $(p)$ from $t$ test. 
Table 4 Concentrations of bile acids in the faecal water (mmol/l) for the three intervention groups

\begin{tabular}{|c|c|c|c|c|c|c|}
\hline & \multicolumn{3}{|c|}{ Before intervention } & \multicolumn{3}{|l|}{ After intervention } \\
\hline & (a) $(n=10)$ & (b) $(n=7)$ & (c) $(n=10)$ & (a) $(n=l(0)$ & (b) $(n=7)$ & (c) $(n=I 0)$ \\
\hline $\begin{array}{l}\text { Lithocholic acid } \\
\text { Median (range) }\end{array}$ & $0 .(07(0-(0 \cdot 59)$ & $0.05(0-0.34)$ & $(0 \cdot 10(0-(0 \cdot 43)$ & $0 \cdot(06(0-0 \cdot 46)$ & $0 .(1) 9(0 \cdot(1) 4-(1) \cdot 3)$ & $0.18(0-0.68)$ \\
\hline $\begin{array}{l}\text { Deoxycholic acid } \\
\text { Median (range) }\end{array}$ & $0.12(0-0 \cdot 84)$ & $(0 \cdot 10(0-0 \cdot 17)$ & $0.25(0 \cdot(07-0 \cdot 48)$ & $0 .\left(18(0-0.52)^{*}\right.$ & $(0.17(0) \cdot(07-(0) 7.3)$ & $0.16(0-(0.59)$ \\
\hline $\begin{array}{l}\text { Total bile acids } \\
\text { Median (range) }\end{array}$ & $0 \cdot 26(0 \cdot(05-1 \cdot 43)$ & $0 \cdot 13(0-(0 \cdot 4.5)$ & $0.38(0 \cdot(17-0.94)$ & $0.14(0-(0.98)$ & $\left(1.36(0 \cdot 16-1.96)^{*}\right.$ & $0.34(0-1 \cdot 12)$ \\
\hline $\begin{array}{l}\text { Total fatty acids } \\
\text { Median (range) }\end{array}$ & $3 \cdot 48(0 \cdot 26-8 \cdot 86)$ & $1.31((1) \cdot 39-1.82)$ & $2 \cdot 51(1 \cdot(08-14 \cdot 25)$ & $1 \cdot 17(0 \cdot 16-9 \cdot 36)$ & $1.99(0.75-5.68)$ & $4.19(0.84-25.82)$ \\
\hline $\begin{array}{l}\text { Total neutral steroids } \\
\text { Median (range) }\end{array}$ & $0 \cdot 22(0 \cdot 06-0 \cdot 86)$ & $0 \cdot 16(0 \cdot(02-1 \cdot 33)$ & $0.38(0 \cdot 08-0.98)$ & $0.11(0 \cdot(02-0) \cdot 9.3)$ & $(1 \cdot 8.3(0 \cdot 27-4 \cdot 2.3)$ & $(1.70)(0 \cdot 0.5-1 \cdot 85)$ \\
\hline
\end{tabular}

*Paired difference between before and after intervention levels significant at $\mathrm{p} \leq 0$ ).(12 by Wilcoxon signed rank test.

thymidine labelling is a measure of the fraction of the cells in the S-phase of the cell cycle and not a measure of the formation of new cells, ${ }^{13}$ and second that the labelling measure is for only one time of observation (when our biopsies were taken) and that the results could be affected by cyclic changes induced by the diets or by the diurnal rhythm. It seems reasonable, however, to take LI as an indicative measure of proliferation at present although the assumptions made must be validated in future studies.

The total quantity of fat consumed by the subjects, $120 \mathrm{~g} \mathrm{fat} / \mathrm{day}$, is not uncommon among populations on Western diets, ${ }^{14}$ but the form used is a substantial simplification of the complex way in which fat is usually incorporated in the diet. It is also not uncommon, however, for Westerners to consume disproportionately higher amounts of fat in their evening meals. We used this simple intervention approach as previous studies with mice had shown that oral boluses of from $0 \cdot 1$ to $0.4 \mathrm{ml}$ corn oil or beef tallow could significantly affect colonic cell proliferation.' We have observed an increase in labelling of the human mucosa after high corn oil consumption that is similar to the increase in labelling and cell proliferation observed in the mice. Interestingly, on a metabolic or area basis, and assuming a weight of 70 $\mathrm{kg}$ and $20 \mathrm{~g}$ for man and mouse respectively, the lower dose of corn oil studied in the mouse corresponds to a dose of only about $20 \mathrm{~g}$ in man $([70000 /$ $20]^{2 / 3} \times 0 \cdot 1 \mathrm{~g}$ ). Perhaps of more importance is the short time scale of these bolus studies. Longer term studies with actual high fat foods are needed to prove that our observations are not transient phenomena.

An effect of age on cell proliferation in individuals on high fat consumption has not been observed before. It is known that mice show more variability in the labelling pattern of their crypts as they age ${ }^{15}$ and it is also known that LI increases with age in animals that have been given colon carcinogens. ${ }^{\text {in }}$ Perhaps the proliferative stress produced by the high fat diet brings out latent defects in the proliteration of the colonic cells in older individuals.

We have also shown that there is all association between the labelling index of the crypt cells and the bile acid concentrations in the corresponding faecal water. This result is consistent with the suggestion that the soluble bile acids induce the colonic proliferation, perhaps as a consequence of epithelial damage. There is, however, neither an exact correlation between the concentration and the proliferation rate nor are the absolute concentrations of bile acids observed as high as those known to produce colonic damage in experimental animals. The lack of exact correlation is perhaps understandable. Other acidic lipids in addition to bile acids could produce epithelial damage and considerable error could be introduced in the analysis of the faccal and colonic specimens because of the variation in position and timing of the samples. The lack of correspondence between the concentrations observed in these studies and those known to produce colonic damage may also be explained. The concentrations that we reported were obtained from stool samples that have been homogenised. The actual concentrations may differ throughout the faccal stream corresponding perhaps, to local $\mathrm{pH}$ or to divalent cation concentrations. Thus a faecal sample with an average concentration of, say, $0.5 \mathrm{mM}$ deoxycholic acid may well have isolated concentrations of $2-3 \mathrm{mM}$ that could lead to epithelial cell damage.

The labelling index has been measured in many cross sectional studies of diseases of the colon and rectum; it is raised in individuals at increased risk for colon cancer. ${ }^{217 \mathrm{k}}$ The results reported here, if confirmed with longer term studies with high fat foods, could provide a possible explanation for the raised levels. Colon cancer risk may be associated with the regular consumption of high fat foods, with high concentrations of acidic lipids in the faecal water, as well as with a raised labelling index. 
Part of this study has been published as an abstract: High fat consumption and age increase colonic crypt activity. Proc Am Assoc Cancer Res 1987; 28: 154.

\section{References}

1 Bird RP. Medline A, Furrer R, Bruce WR. Toxicity or orally administered fat to the colonic epithelium. Carcinogenesis 1985; 6: 1063-6.

2 Bird RP. Stamp D. Effect of high fat diet on the murine colonic epithclium. Cancer Lett 1986; 31: 61-7.

3 Rafter JJ, Eng VW, Furer R, et al. The effect of calcium and $\mathrm{pH}$ on the mucosal damage produced by deoxycholic acid in the rat colon. Gut 1986; 27: 1320-9.

4 Goerg KJ. Specht W, Nell G, Dummel W. Schultz L. Effect of deoxycholate on the perfused rat colon. Scanning and transmission electron microscopic study of the morphological alterations occurring during the secretagogal action of deoxycholate. Digestion 1982; 25: 145-54.

5 Rafter JJ, Child P, Anderson AM, Alder R, Eng VW, Bruce WR. Cellular toxicity of fecal water depends on diet. Am J Clin Nutr 1987; 45: 559-63.

6 Child P, Aloe M, Mee D. Separation and quantitation of fatty acids, sterols and bile acids in feces by gas-liquid chromatography as the butylester/acetate derivatives. $J$ Chromatogr 1987; 415: 13-26.

7 Meyer JS, Bauer WC. In vitro determination of tritiated thymidine labelling index. Cancer 1975; 36: 1374-80.

8 Usugane M, Fujita M. Palmer R, et al. Cell proliferation in explant cultures of human colon. Digestion 1982; 24: 225-33.

9 SAS Institute Inc. $S A S$ users guide. North Carolina: Cary, 1982.
10 Fleiss JL. Statistical methods for rates and proportions. New York: John Wiley, 1981.

11 Lipkin M, Newmark $\mathrm{H}$. Effect of added dietary calcium on colonic epithelial cell proliferation in subjects at high risk for familial colon cancer. $N$ Engl J Med 1985; 313: 1381-4.

12 Terpstra OT, van Blankenstein M, Dees J, Eilers GA. Abnormal pattern of cell proliferation in the entire colonic mucosa of patients with colon adenoma or cancer. Gastroenterology 1987; 92: 704-8.

13 Wright AN. Cell proliferation in the normal gastrointestinal tract. Implications for proliferative responses. In: Appleton RD. Sunter JP. Watson JA, eds. Cell proliferation in the gastrointestinal tract. London: Pitman Medical Press, 198(): 3-21.

14 McKeown-Eyssen GE, Yeung KS, Bright-Sec E. Assessment of past diets in epidemiologic studies. Am J Epidemiol 1986: 124: 94-103.

15 Fry MJR, Tyler AS, Lesher S. Relationships between age and variability. In: Lindop PJ. Sacher GA, eds. Radiation and ageing. London: Taylor and Francis, 1966.

16 Wargovich MJ, Medline A, Bruce WR. Early histopathologic events to evolution of colon cancer in $\mathrm{C} 57 \mathrm{BL} / 6$ and CF1 mice treated with 1,2-dimethylhydrazine. J Natl Cancer Inst 1983; 71: 125-31.

17 Lipkin M. Vehara K. Winawer S, et al. Seventh Day Adventist Vegetarians have a quiescent proliferative activity in colonic mucosa. Cancer Lett 1985; 26: 139-44.

18 Lipkin M. Blattner AW, Gardner JE, et al. Classification and risk assessment of individuals with familial polyposis, Gardner's Syndrome, and familial nonpolyposis colon cancer from ' $H$ thymidinc labelling patterns in colonic epithelial cells. Cancer Res 1984; 44: 4()21-7. 